\title{
Crescimento inicial de plantas de pinhão manso em função do sombreamento no município de Gurupi-TO
}

\author{
Initial growth of plants of physic nut under shading in the Gurupi \\ county, Tocantins State, Brazil
}

\author{
Jefferson da Luz Costa ${ }^{1,2^{*}}$, Ronaldo Pereira Lima ${ }^{2}$, André Luís Lopes da Silva ${ }^{1}$, Gessiel \\ Newton Scheidt ${ }^{2}$ e Eduardo Andrea Lemus Erasmo ${ }^{2}$
}

\author{
${ }^{1}$ Departamento de Engenharia de Bioprocessos e Biotecnologia; Universidade Federal do Paraná; 81531-970; \\ Curitiba - PR - Brasil. ${ }^{2}$ Departamento de Ciências Agrárias e Tecnológicas; Universidade Federal do Tocantins; \\ 77402-970; Gurupi - TO - Brasil.
}

\begin{abstract}
The growth analysis has been used by researchers to explain differences in the growth, which can be caused for genetic factors or by environmental modifications and constitutes efficient tool for the identification of favorable environments, besides identifying characteristics in the initial growth, to indicate possibility in the increase of growth of the adult plant, favoring the genetic breeding for material more productive. The aim of this research was to study the initial growth of the physic nut (Jatropha curcas L.) in three shading levels $(0 \%, 50 \%$ and $90 \%)$. The evaluated variables were height of plants, stem base diameter, leaf area, dry mass of the leaves, total dry mass and number of leaves at the 7,14,21,28, 35 and 42 days after the emergency of the plants. The largest height of the plants was observed in $50 \%$ of shading and the smallest in $0 \%$ of shading. The largest stem base diameter was obtained in plants with $0 \%$ of shading and the smallest in $90 \%$. Plants cultivated on $50 \%$ of shading presented larger number of leaves, leaf area, dry mass of the leaves and total dry mass. The best development of seedlings of physic nut occurs under $50 \%$ of shading in the Gurupi, TO.
\end{abstract}

Key words: Jatropha curcas, luminosity, Euphorbiaceae, growth analysis

\section{INTRODUÇÃO}

O pinhão-manso (Jatropha curcas L.) é uma planta perene pertencente à família Euphorbiaceae, ocorrendo no Brasil, de fácil cultivo, porém, ainda em processo de domesticação. Além disso, é amplamente distribuído em áreas tropicais e subtropicais, e até em algumas áreas temperadas (Costa et al., 2010; Santos et al., 2011). O cultivo de pinhão manso no Cerrado vem se expandindo de forma acelerada (Pereira et al., 2011). O óleo apresenta variações pouco significativas na acidez, além de possuir melhor estabilidade à oxidação do que o de soja. Esta planta é promissora por apresentar elevado teor de óleo (25 a 40\%), superior ao da maioria das oleaginosas utilizadas no mercado de biocombustíveis (Arruda et al., 2004). Esta espécie se propaga por sementes e vegetativamente, apesar disso, procedimentos para a produção de mudas são muitos escassos. Assim, o conhecimento do crescimento das plantas no viveiro, em resposta a fatores como água, luz, temperatura, fertilizantes e restrição radicial é importante para a produção de mudas de qualidade e em grande quantidade (Saturnino et al., 2005).

A análise de crescimento tem sido usada por pesquisadores na tentativa de explicar diferenças no crescimento de ordem genética ou resultante de modificações do ambiente e constitui ferramenta eficiente para a identificação de ambientes favoráveis, além de identificar características que, no crescimento inicial, indiquem possibilidade de aumento no rendimento da planta adulta, favorecendo os trabalhos de melhoramento na busca de materiais mais produtivos.

Author for correspondence: jeff@uft.edu.br 
O fundamento da análise de crescimento baseia-se no fato de que, em média, $90 \%$ da matéria orgânica acumulada ao longo do crescimento da planta resultam da atividade fotossintética e o restante, da absorção mineral do solo (Benincasa, 1988). O acúmulo de matéria seca e o incremento da área foliar quantificados em função do tempo, são utilizados na estimativa de vários índices fisiológicos relacionados às diferenças de desempenho entre cultivares ou diferentes materiais da mesma espécie e das comunidades vegetais nos diversos estudos ecofisiológicos.

A eficiência no crescimento da planta pode estar relacionada à habilidade de adaptação das plântulas às condições luminosas do ambiente. $\mathrm{O}$ objetivo desse trabalho foi avaliar o crescimento inicial de Jatropha curcas L. em três níveis de sombreamento em função do tempo no municipio de Gurupi, TO.

\section{MATERIAL E MÉTODOS}

\section{Localização do Experimento}

$\mathrm{O}$ trabalho foi conduzido na área experimental da Universidade Federal do Tocantins (UFT), Campus Universitário de Gurupi, localizado na região sul do Estado do Tocantins. A altitude da área experimental é de $280 \mathrm{~m}$, e $11^{\circ} 43^{\prime} 45^{\prime \prime}$ de latitude e $49^{\circ} 04^{\prime} 07^{\prime \prime}$ de longitude. A classificação climática da área experimental, segundo a classificação de KÖPPEN, é do tipo B1wA'a' úmido com moderada deficiência hídrica. A temperatura média anual é de $29,5{ }^{\circ} \mathrm{C}$, com precipitação anual média de $1804 \mathrm{~mm}$, sendo um verão chuvoso e um inverno seco. $\mathrm{O}$ experimento foi conduzido no período de 24/09/2008 à $08 / 11 / 2008$. As sementes utilizadas foram semeadas em sacos plásticos de polietileno contendo $500 \mathrm{~g}$ de substrato orgânico.

\section{Condições de cultivo e delineamento experimental}

Os níveis de sombreamento foram: $0 \%$ de sombreamento, $50 \%$ de sombreamento e em sombra natural de árvores com 90\% de sombreamento. $\mathrm{O}$ percentual de sombreamento natural foi mensurado por meio de um medidor de dossel foliar modelo SunScan Canopy Analyser SS1-UM-1.05. O tratamento $1 \quad(0 \%$ de sombreamento) foi conduzido em um local com incidência total de luz, o tratamento $2(50 \%$ de sombreamento) foi obtido com tela de polietileno de coloração preta (sombrite) e no tratamento 3 ( $90 \%$ de sombreamento) com sombra natural, as mudas foram colocadas em uma área remanescente de vegetação nativa do cerrado.
Após 10 dias da emergência das plantas foram iniciadas as avaliações totalizando seis amostragens $(7,14,21,28,35$ e 42 dias após a emergência das plantas-DAE). A irrigação foi feita no intervalo de um dia sempre no final da tarde de forma manual.

Foram avaliados em cada amostragem: altura de planta $(\mathrm{AP} \mathrm{cm})$, diâmetro de colo (DC $\mathrm{mm})$, número de folhas (NF), massa seca de folhas (MSF g), massa seca total (MST g). A equação a ser utilizada para obtenção da área foliar foi $(\mathrm{A}=0,84(\mathrm{CxL}) \mathrm{x} 0,99)$ que utiliza as duas variáveis estudadas (nervura principal e largura) segundo método proposto por Severino et al., (2007).

O delineamento estatístico utilizado foi blocos inteiramente casualizados, onde os tratamentos constituíram-se em três níveis de sombreamento e quatro repetições, sendo cada planta considerada como uma repetição. Para garantir 36 plantas foram semeadas $20 \%$ a mais de sementes em cada tratamento com o monitoramento diário de germinação. Os resultados foram submetidos à análise de regressão ao nível de $5 \%$ de probabilidade de erro.

\section{RESULTADOS E DISCUSSÃO}

A altura das plantas de pinhão manso desenvolvidas sob diferentes condições de sombreamento em função do tempo apresentou um crescimento linear positivo para todos os tratamentos (Figura 1).

A menor altura das plantas de pinhão manso foi verificada no tratamento de $0 \%$ de sombreamento. Aos 42 dias (DAE) a altura das plantas correspondia a $22,67,18,55$ e $15,5 \mathrm{~cm}$, para os tratamentos $50 \%, 90 \%$, e $0 \%$ de sombreamento, respectivamente. Os resultados obtidos concordam com alguns trabalhos na literatura realizados com espécies lenhosas, nas quais a maior altura ocorre em condições sombreadas (Mazzei et al., 1998; Felfili et al., 1999; Atroch et al., 2001).

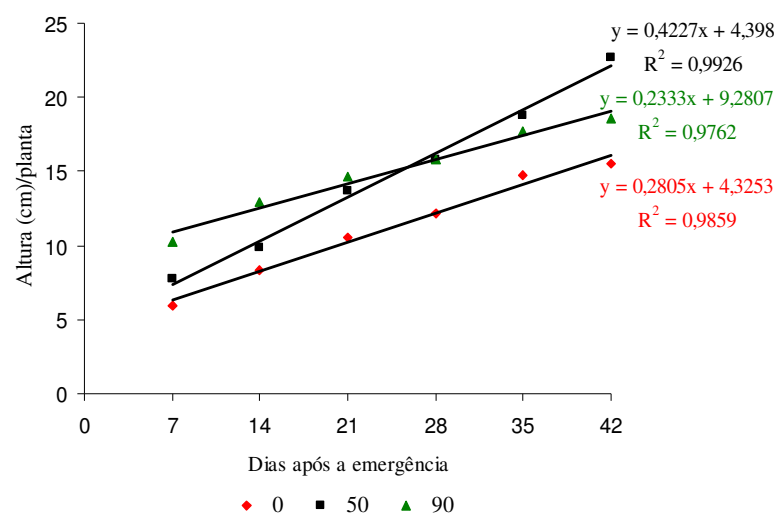

Figura 1 - Altura de Planta de pinhão manso sob diferentes níveis de sombreamento $(0 \%, 50 \%$ e $90 \%)$. 
$\mathrm{O}$ diâmetro do caule em função do tempo nas mudas de pinhão manso desenvolvidas sob diferentes percentagens de sombreamento, também seguiu um efeito linear positivo ao longo do tempo (Figura 2). Este aumento foi mais representativo a partir do $14^{\circ}$ dia após a emergência (DAE), no qual ficou evidente a superioridade do tratamento $0 \%$ de sombreamento atingindo valores de $9,78 \mathrm{~mm}$ aos 42 dias (DAE).

$\mathrm{O}$ diâmetro do colo das mudas do tratamento de $50 \%$ de sombreamento foi menor que do tratamento $0 \%$ e maior que o de $90 \%$ de sombreamento. $\mathrm{O}$ diâmetro do caule do tratamento de $90 \%$ aos 42 dias (DAE) foi $42 \%$ menor do que aquele verificado para o tratamento $0 \%$ de sombreamento no mesmo período. No entanto, outros autores têm verificado a tendência de maiores diâmetros do caule quando as plantas são submetidas a condições sombreadas (Mazzei et al., 1998; Mazzei et al., 1999).

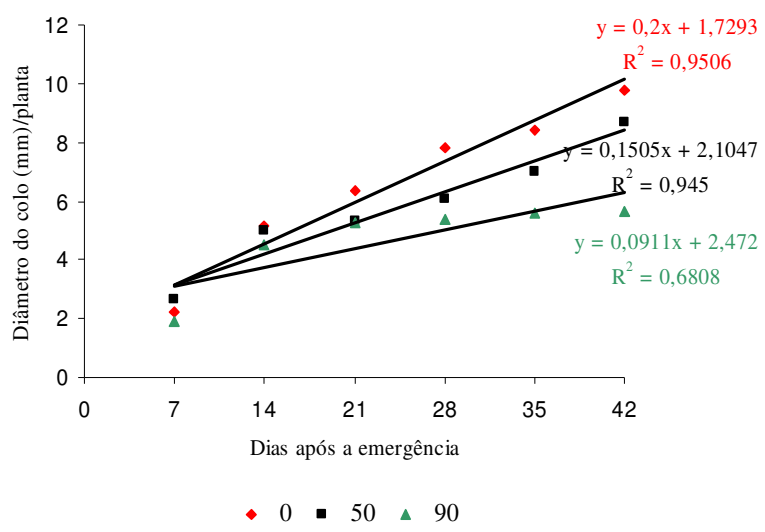

Figura 2 - Diâmetro do colo da planta de pinhão manso sob diferentes níveis de sombreamento $(0 \%$, $50 \%$ e $90 \%$ ).

O número de folhas de mudas de pinhão manso ao longo do tempo para diferentes porcentagens de sombreamento seguiram um comportamento linear positivo, entretanto a $50 \%$ de sombreamento este incremento foi maior (Figura 3). Valores intermediários foram verificados para o tratamento de $0 \%$ de sombreamento e menores para o de $90 \%$. Resultados semelhantes foram observados no desenvolvimento inicial de plântulas de Theobroma grandiflorum (Willd. ex Spreng.) Schum. (Silva et al. 2006).

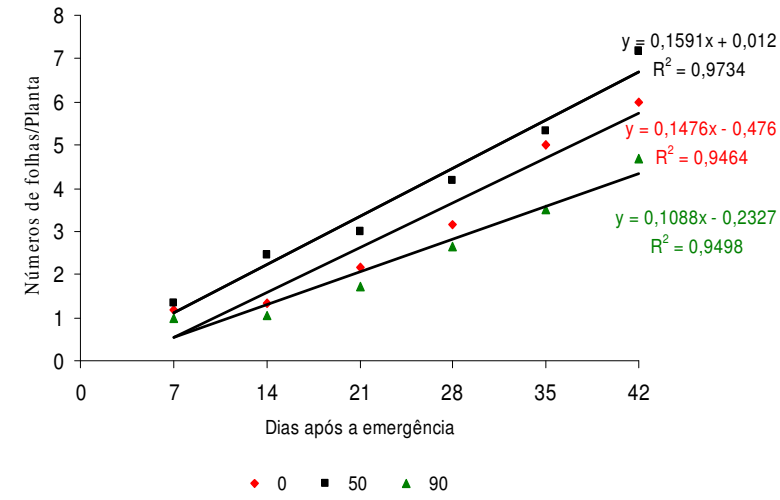

Figura 3 - Número de folhas de plantas de pinhão manso sob diferentes níveis de sombreamento $(0 \%$, $50 \%$ e $90 \%$ ).

A área foliar total das mudas cultivadas sob diferentes percentagens de sombreamento ao longo do tempo seguiu um efeito linear positivo (Figura 4). Ficou evidente a superioridade no tratamento com $50 \%$ de sombreamento com um grande incremento a partir do $7^{\circ}$ dia (DAE).

Aos 42 dias (DAE) foram constatadas áreas foliares na ordem de 286,58, 187,21 e 126,86 $\mathrm{cm}^{2}$, para os tratamentos 50\%, 0\%, e 90\%, respectivamente. A área foliar constatada no tratamento de $50 \%$ foi 2,2 vezes maior que aquela contatada para o tratamento de $90 \%$. Resultados semelhantes foram observados por Farias et al. (1997), estudando o desenvolvimento das mudas de cedrorana (Cedrelinga catanaeformis (Ducke) Ducke) sob pleno sol, 30; 50 e 70\% de luz.

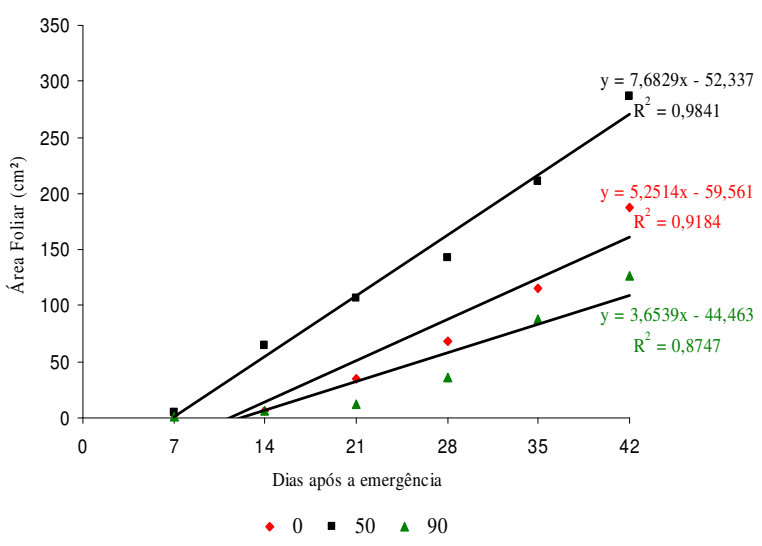

Figura 4 - Área foliar de planta de pinhão manso sob diferentes níveis de sombreamento $(0 \%, 50 \%$ e $90 \%)$.

O acúmulo de massa seca de folhas em função do tempo para plantas cultivadas sob diferentes porcentagens de sombreamento também seguiram um efeito linear positivo (Figura 5). Maiores 
incrementos de massa seca no tempo foram constatados para o tratamento de $50 \%$ de sombreamento seguido pelos tratamentos de $0 \%$ e $90 \%$. Massa seca de folhas acumuladas aos 42 dias (DAE) pelas plantas cultivadas em $50 \%$ foi 1,4 e 4,5 maiores que aquelas constatadas nos tratamentos de $0 \%$ e $90 \%$, respectivamente. Maior massa seca de folhas foi obtida em plantas de Sclerolobium paniculatum cultivadas sob $50 \%$ de sombreamento e menor nas plantas cultivadas sob 90\% de sombreamento (Felfili et al., 1999).

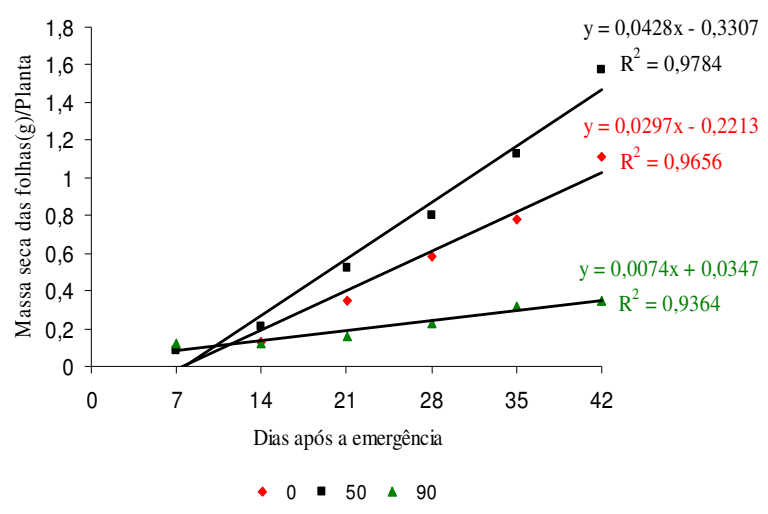

Figura 5 - Massa seca foliar de plantas de pinhão manso sob diferentes níveis de sombreamento $(0 \%$, $50 \%$ e $90 \%$ ).

A tendência verificada em relação à massa seca total foi semelhante a partir dos 14 dias (DAE) (Figura 6). Para os tratamentos de 50\%, 0\% e $90 \%$ de sombreamento foram constatados valores de massa seca total de 2,6, 1,86 e $0,75 \mathrm{~g}$, respectivamente. $\mathrm{O}$ valor verificado no tratamento de $50 \%$ foi 3,05 vezes maior do que aquele constatado no tratamento de $90 \%$.

A resposta de acúmulo da massa seca é variável, devido cada espécie possuir características genéticas diferentes e conseqüentemente, adaptações fisiológicas diferentes. De acordo com Kitao et al. (2000), a exposição prolongada a altas irradiâncias pode ser prejudicial às plântulas, por absorverem mais luz do que podem utilizar, podendo ter como conseqüência a fotoinibição ou, mesmo, a morte da planta.

A superioridade verificada no tratamento de $50 \%$ de sombreamento poderá esta relacionada com condições de temperatura e umidade melhores para $\mathrm{o}$ crescimento das plantas, enquanto $\mathrm{o}$ tratamento $0 \%$ mesmo com maior quantidade de luminosidade e maior temperatura, menor umidade reduziram o crescimento das folhas e das plantas em comparação ao de $50 \%$. Com relação ao tratamento de $90 \%$, que houve menor crescimento, pode ser devido à baixa disponibilidade de luz a qual ocasionou uma redução da atividade fotossintética expressa no acúmulo de massa seca das plantas.

No sombreamento de $90 \%$ não foi observado maior área foliar nas plantas em função da deficiência de luz.

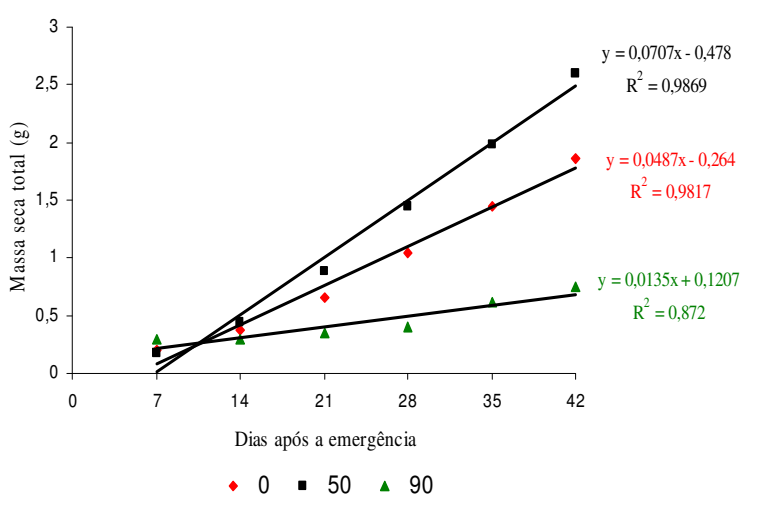

Figura 6 - Massa seca total de plantas de pinhão manso sob diferentes níveis de sombreamento (0, 50 e $90 \%)$.

\section{CONCLUSÃO}

O melhor desenvolvimento de mudas de pinhão manso ocorre em $50 \%$ de sombreamento nas condições de Gurupi, TO.

\section{RESUMO}

A análise de crescimento tem sido usada por pesquisadores, na tentativa de explicar diferenças no crescimento, de ordem genética ou resultante de modificações do ambiente e constitui ferramenta eficiente para a identificação de ambientes favoráveis, além de identificar características que, no crescimento inicial, indiquem possibilidade de aumento no rendimento da planta adulta, favorecendo os trabalhos de melhoramento na busca de materiais mais produtivos. Este trabalho foi realizado visando estudar o crescimento inicial do pinhão manso (Jatropha curcas L.) em três níveis de sombreamento $(0 \%, 50 \%$ e $90 \%$ ). Os parâmetros avaliados foram altura de plantas, diâmetro de colo, área foliar, massa seca das folhas, massa seca total e número de folhas aos 7, 14, 21, 28, 35 e 42 dias após a emergência das plantas. A maior altura das plantas foi observada em $50 \%$ de sombreamento e a menor em $0 \%$ de sombreamento. $\mathrm{O}$ maior diâmetro do colo foi obtido em plantas com $0 \%$ de sombreamento e o menor em 90\%. Plantas cultivadas sobre $50 \%$ de sombreamento apresentaram maior número de folhas, área foliar, massa seca das folhas e massa seca total. O melhor desenvolvimento de mudas de pinhão manso ocorre em $50 \%$ de sombreamento em Gurupi, TO.

Palavras-chave: Jatropha curcas, análise de crescimento, luminosidade, Euphorbiaceae 


\section{REFERÊNCIAS}

Arruda, F. P.; Beltrão, N. E. M.; Andrade, A. P.; Pereira, W. E.; Severino, L. S. (2004), Cultivo de pinhão manso (Jatropha curcas L.) como alternativa para o semi-árido nordestino. Revista Brasileira de Oleaginosas e Fibrosas, Campina Grande, 8, 789-799.

Atroch, E. M. A. C.; Soares, A. M.; Alvarenga, A. A.; Castro, E. M. (2001), Crescimento, teor de clorofilas, distribuição de biomassa e características anatômicas de plantas jovens de Bauhinia forticata LINK submetidas à diferentes condições de sombreamento. Ciência $e$ Agrotecnologia, 25, 853-862.

Benincasa, M. M. P. (1988), Análise de crescimento de plantas (noções básicas). Jaboticabal: FCAV-UNESP. 42 p.

Costa, J. L.; Silva, A. L. L.; Scheidt, G. N.; Lemus, E. A. E.; Soccol, C. R. (2010), Estabelecimento in vitro de sementes de pinhão manso (Jatropha curcas L.) - Euphorbiaceae. Caderno de Pesquisa Série Biologia, 22, 5-12.

Farias, V. C. C.; Costa, S. S.; Batalha, L. F. P. (1997), Análise de crescimento de mudas de cedrorana (Cedrelinga catenaeformis (Ducke) Ducke) cultivadas em condições de viveiro. Revista Brasileira de Sementes, Brasília, 2, 193200.

Felfili, J. M. (1999), Comportamento de plântulas de Sclerolobium paniculatum Vog. var. rubiginosum (Tul.) Benth. sob diferentes níveis de sombreamento, em viveiro. Revista Brasileira de Botânica, 2, 297-301. Suplemento.

Kitao, M.; Lei, T. T.; Koike, T.; Tobita, H.; Maruyama, Y. (2000), Susceptibility to photoinhibition of three deciduous broadleaf tree species with different successional traits raised under various light regimes. Plant, Cell and Environment, 23, 81-89.
Mazzei, L. J.; Felfili, J.M.; Rezende, A.V.; Franco, A.C.; Sousa-Silva, J.C.; (1998), Crescimento de plântulas de Schefflera morototoni (Aubl.) Maguire, Steyermark e Frodin em diferentes níveis de sombreamento no viveiro. Boletim do Herbário Ezechias Paulo Heringer, Brasília, 3, 27-36.

Mazzei, L. J.; Sousa-Silva, J.C.; Felfili, J.M.; Rezende, A.V.; Franco, A.C.; (1999), Crescimento de plântulas de Hymenaea coubaril L. var. stilbocarpa (Hayne) Lee e Lang. em viveiro. Boletim do Herbário Ezechias Paulo Heringer, Brasília, 4, 21-29.

Pereira, J. C. S.; Fidelis, R. R.; Erasmo, E. A. L.; Santos, P. M.; Barros, H. B.; Carvalho, G. L. (2011), Florescimento e frutificação de genótipos de pinhão manso sob doses de fósforo no cerrado da Região Sul do Tocantins. Journal of Biotechnology and Biodiversity, 2, 28-36.

Santos, P. M.; Fidelis, R. R.; Pereira, J. C. S.; Erasmo, E. A. L.; Barros, H. B.; Carvalho, G. L. (2011), Formas e épocas de amostragem em folhas de pinhão manso para quantificação da área foliar. Journal of Biotechnology and Biodiversity, 2, 5157.

Saturnino, H. M.; Pacheco, D. D. ; Kakida , J. ; Tominaga, N.; Gonçalves , N. P. (2005), Cultura do pinhão-manso (Jatropha curcas L.). Informe agropecuário, Belo Horizonte, 229, 44-78.

Severino, L. V.; Vale, L.S.; Beltrão, N.E. (2007), A simple method for measurement of Jatropha curcas leaf area. Revista Brasileira de Oleaginosas e Fibrosas, Campina Grande, 1, 9-14.

Silva, R. R.; Freitas, G. A.; Siebeneichler, S. C.; Mata, J. F.; Chagas, J. R. (2006), Desenvolvimento inicial de plântulas de Theobroma grandiflorum (Willd. ex Spreng.) Schum. sob influência de sombreamento. Acta Amazônica, 3, 365-370. 